STAT3 the oncogene - Still eluding therapy?

Matthew S Wake and Christine J Watson

Department of Pathology, University of Cambridge, Tennis Court Road, Cambridge CB2 1QP, UK

\begin{abstract}
The STAT family of transcription factors transduce signals from cytokine receptors to the nucleus where STAT dimers bind to DNA and regulate transcription. STAT3 is the most ubiquitous of the STATs being activated by a wide variety of cytokines and growth factors. STAT3 has many roles in physiological processes such as inflammatory signalling, aerobic glycolysis, and immune suppression and was also the first family member shown to be aberrantly activated in a wide range of both solid and liquid tumours. STAT3 promotes tumourigenesis through regulating the expression of various target genes including cell cycle regulators, angiogenic factors and anti-apoptosis genes. Paradoxically, in some circumstances STAT3 signalling induces cell death. The best known example is the involuting mammary gland where STAT3 is essential for the induction of a lysosomal pathway of cell death. Nevertheless, direct silencing or inhibition of STAT3 diminishes tumour growth and cell survival in both animal and human studies. This suggests that abolishing STAT3 activity could be an effective cancer therapeutic strategy. However, despite this potential as a therapeutic target and the extensive attempts by academia and pharmaceutical companies to develop an effective STAT3 inhibitor for use in the clinic, there has not been a single, direct STAT3 inhibitor approved for clinical use. In this review, we will focus on the role of STAT3 in tumourigenesis and discuss its potential as a therapeutic target for cancer treatment.
\end{abstract}

\title{
Introduction
}

The signal transducers and activators of transcription (STATs) are a family of seven proteins of close homology, STAT1, STAT2, STAT3, STAT4, STAT5a and closely related STAT5b, and STAT6. There are four known isoforms of human STAT3 located on chromosome 17q21.31 (1). STAT3 $\alpha$, the predominantly expressed isoform, is a 770 amino acid, $88 \mathrm{kDa}$ protein that elicits most functions ascribed to STAT3 (2). STAT3 $\beta$, an alternatively spliced variant, lacks the C-terminal domain and was described as a dominant negative form until evidence showed it to be a functional 
transcription factor (3). STAT3 $\gamma$ and STAT3 $\delta$, the lesser well known STAT3 isoforms, may have roles in neutrophil and granulocytic differentiation respectively $(4,5)$. The structure of STAT3 is typical of the STAT family, comprising an Nterminal domain, a coiled-coil domain, a Src homology 2 (SH2) domain, a DNA binding domain and a C-terminal transactivation domain (Figure 1) (6). The $\mathrm{N}$ terminal coiled-coiled domain forms an interface for dimer-dimer interactions during STAT3-driven initiation of gene expression $(7,8)$. The $\mathrm{SH} 2$ domain contains three important solvent accessible subpockets that stabilize STAT-STAT dimer interactions and STAT3-receptor binding interactions (9). The DNA-binding domain provides the protein-DNA binding interface, whereby upon activation, individual STAT monomers dimerize completing a nutcracker-like structure which binds to specific DNA motifs, initiating transcription (10).

\section{STAT3 activation}

STAT3 activation is mediated primarily by IL-6 family cytokine receptor-associated Janus kinases (JAKs) although receptor tyrosine kinases such as EGFR and nonreceptor tyrosine kinases such as Src can also phosphorylate STAT3 (Figure 2) (1113). Following JAK activation, latent cytosolic STAT3 monomers dock with cytokine-bound receptors at pTyr sites through $\mathrm{SH} 2$ domain binding, whereupon JAKs phosphorylate STAT3 on a conserved tyrosine residue (pTyr705) found in the C-terminal region. Post-phosphorylation, STAT3 monomers dissociate from receptor docking sites and dimerize through reciprocal pTyr and SH2 domain interactions (14). STAT3 is known to form homo and heterodimers with STAT1 due to the high sequence similarity between the two proteins, diversifying the number of genes under their transcriptional control (15). STAT3 can also be further modified by phosphorylation on a serine residue (S727) in the C-terminal region to promote full STAT3 activation. This serine residue, important in prolonging retention in the nucleus and affecting overall growth, is only present on the STAT3 $\alpha$ isoform $(16,17)$. STAT3 can also be acetylated at Lys685 to alter expression of specific gene targets (18).

\section{STAT3 regulation}

STAT3 dimers regulate transcription of a variety of genes through binding to canonical palindromic $\mathrm{CCT}(\mathrm{N})_{3} \mathrm{GAA}$ sites in the promoter regions of target genes. 
Collectively, each STAT member elicits a wide range of important cellular responses and although DNA binding sites appear to be shared, each STAT displays specific gene expression signatures that seem to be cell type dependent (19). Expression and activation of STAT3 is exquisitely regulated in normal cells with a plethora of factors that silence JAK/STAT signalling. These include SOCS (suppressor of cytokine signalling) proteins that can bind to activated JAKs or receptor domains and efficiently block STAT phosphorylation. SOCS3 is a direct transcriptional target of STAT3, providing a cellular negative feedback mechanism for STAT3 signalling (20). The PIAS family (protein inhibitor of activated STAT) are a family of SUMOE3 ligases that covalently attach SUMO proteins to target substrates, thus altering their activity. PIAS3 in particular has been shown to directly inhibit STAT3 activity through this post translational modification (21). In addition to these, PTPs (protein tyrosine phosphatases), SHPs (Src homology domain-containing tyrosine phosphatases) and the more recently discovered PTPRT (protein tyrosine phosphatase receptor T) can specifically dephosphorylate STAT3 and upstream kinases in the JAK-STAT pathway to terminate STAT3 signalling (22).

\section{STAT3 as an oncogene}

STAT3 was first noted to be constitutively active in breast cancers (23). It became directly associated with oncogenic signalling when cells transformed by HTLV-1 and EBV viral infections were found to have constitutive STAT3 activity, a result of increased tyrosine kinase activity $(24,25)$. Furthermore, blocking STAT3 activity decreases cellular transformation in v-Src transformed cell lines (26). Further evidence that STAT3 is an oncogene was provided by expressing a mutated STAT3 construct (STAT3C), that constitutively forms dimers, in normal mouse fibroblasts which, when transplanted into nude mice, formed tumours (27). This STAT3C construct was found to drive tumour formation in a variety of cell types by upregulating important oncogenic and angiogenic factors such as MMP-9, VEGF, and Cten (28-30).

During tumourigenesis, STAT3 activity can become dysregulated, despite the impressive array of negative regulators of STAT3 signalling. Abnormal persistent STAT3 activity has been demonstrated in multiple haematological and solid cancers (31). Of notable interest, constitutive STAT3 activity is found in a high percentage of triple negative breast cancers and in $30-60 \%$ of all primary breast cancers (32). 
Unlike most oncogenes, STAT3 mutations that contribute to aberrant STAT3 signalling are not frequently found in tumours. A rare exception is the STAT3 SH2 domain somatic mutations that were found in $12 \%$ of inflammatory hepatocellular adenomas that lacked mutations in the IL-6 receptor, which sensitized STAT3 proteins to activation and homo-dimerization independently of IL-6 (33). In the majority of cases, however, persistent STAT3 activation occurs through deregulated upstream signalling where kinases that phosphorylate STAT3 can become overexpressed or constitutively activated $(32,34)$.

The primary distinction between STAT3 activation in normal and cancer cells is the level and duration of signalling. While cytokine-mediated activation of STAT3 is substantial and acute, oncogene-mediated STAT3 activation is generally at a lower level and prolonged (35). Some cancers become dependent upon, or addicted to this activity such that STAT3 inhibition restricts tumour growth and can induce cell death (36). In addition to the tumour cells themselves, STAT3 activity in the tumour microenvironment plays a major role in tumour progression and metastasis. STAT3 activation can induce expression of inflammatory cytokines such as IL-6 and angiogenic factors such as HIF1 $\alpha$ and VEGF $(30,37)$. These inflammatory mediators promote wound healing but also influence cells in the tumour microenvironment via further induction of the JAK/STAT3 pathway $(37,38)$. Indeed, cancer has been considered as a wound that does not heal. The release of inflammatory and angiogenic factors driven by STAT3 in this microenvironment has suppressive effects on the immune system. Immature dendritic cells (DCs) are prevented from differentiating into antigen presenting cells, while macrophage expression of factors that promote Th1-mediated adaptive immune responses are suppressed $(39,40)$. Persistent STAT3 activation in immature myeloid cells (iMCs) and naïve T-cells, promoted by STAT3 induced cytokines, expands the populations of myeloid derived suppressor cells (MDSCs) and T regulatory (Treg) cells $(41,42)$. Treg cells directly inhibit CD4+ and CD8+ $\mathrm{T}$ cells through a cell-contact-dependent mechanism and induction of suppressive factors such as TGF- $\beta$ and IL-10, aiding tumour immune evasion (42-44). Complete STAT3 ablation from the myeloid lineage leads to increased immune responses due to increased macrophage activation and production of Th1 cytokines (40). STAT3 ablation from the hematopoietic lineage produces a similar result with increases in activation of dendritic, natural killer and T-cells, resulting in suppressed tumour growth (42). 


\section{STAT3 as a viable therapeutic target: effects of inhibition on cancer growth}

As mentioned above, tumour cells are often highly susceptible to STAT3 inhibition or ablation $(42,45)$. This is not surprising since STAT3 signalling promotes proliferation through the up regulation of cell cycle regulators such as cyclins D1, and D3 and c-Myc $(45,46)$. A variety of STAT3 inhibitors, including chemicals, decoy peptides and siRNA reagents have been developed, albeit often with limited efficacy (47, 48). STAT3 inhibition or siRNA knockdown has been shown repeatedly to increase cell death and reduce growth of tumours both in vivo and in vitro. For example, STAT3 inhibitor treatment of malignant glioma xenograft models suppressed the expression of c-Myc, Bcl-xL and $\mathrm{Mcl}-1$, and induced apoptosis (49)while siRNA-mediated STAT3 inhibition in laryngeal tumours down regulated Bcl-2, survivin, and cyclin D1 protein levels and also induced apoptosis (50). In addition, STAT3 RNAi knockdown in aggressive breast cancer cell lines increased expression of apoptotic proteins Fas/Fas-L, while decreasing expression of antiapoptotic genes Bcl-xL and survivin, to induce apoptosis in vitro and in vivo (51). STAT3 is also implicated in epithelial-to-mesenchymal transition (EMT) which can contribute to invasion and metastasis. Transcription factors known to promote EMT, such as Twist and Snail are up regulated in cancers with aberrant STAT3 activity and STAT3 is required for TGF- $\beta$-induced EMT $(52,53)$. Consequently, STAT3 inhibition reduces expression of these genes leading to reduced cancer cell invasion (53). Finally, persistent STAT3 signalling also directs cancer cells towards aerobic glycolysis, increasing proliferation and survival (54). Taken together, it is clear that STAT3 is implicated in multiple features of cancer cells highlighting the unmet need for effective inhibitors.

In this context it is interesting to note that STAT3 inhibition in adult mice and recent human trials produced only moderate side effects in differentiated tissues suggesting that STAT3 drugs may not be highly toxic and encouraging the further development of STAT3 therapeutics $(51,55,56)$. In addition, STAT3 inhibition sensitizes cancer cells to chemotherapeutic agents, highlighting the potential for STAT3 inhibitors in combinational cancer therapy $(57,58)$. However, STAT3 inhibitors need to be able to distinguish between STAT3 and STAT1 to be useful in a clinical setting. STAT3 and STAT1, although structurally very similar, display key differences in transcriptional 
targets. STAT1 provides an important anti-viral mechanism and is also a known tumour suppressor $(59,60)$.

\section{Strategies for inhibiting STAT3 signalling}

\subsection{Indirect targets}

Most cases of persistent STAT3 activation are caused by activating mutations in, or overexpression of, upstream kinases such as JAK2, Src and EGFR. A decrease in expression of STAT3 negative regulators such as SOCS and PIAS, as observed in hepatocellular carcinoma and mesothelioma tumours respectively, can also result in constitutive STAT3 activity $(61,62)$. Several drugs that can target these components are already in clinical trials or in use in the clinic, including the JAK2 inhibitor Ruxolitinib and the EGFR blocking antibody Cetuximab (63, 64). Furthermore, key methyltransferases and acetyltransferases specific to STAT3 could also be targeted as additional therapeutic options for STAT3 inhibition $(65,66)$.

Overexpression of EGFR can contribute to aberrant STAT3 activity and is abundant in squamous cell carcinoma of the head and neck (SCCHN), a leading cause of death worldwide (67). EGFR is also overexpressed in approximately $16-36 \%$ of all breast carcinomas and may harbour activating mutations (68).

Aberrant STAT3 activity in cancer is also frequently caused by overactive members of the JAK family $(32,34)$. A breakthrough in understanding myeloproliferative diseases occurred after discovering JAK2 activating mutations leading to a novel class of oral JAK2 inhibitors (69). As such, many FDA-approved JAK kinase specific inhibitors are now in clinical use for cancer treatment. Ruxolitinib, the first FDAapproved JAK1 and JAK2 specific kinase inhibitor for myeloproliferative disease treatment, is now prescribed for other types of cancer with constitutive STAT3 activity, such as lymphomas and pancreatic cancer (70, 71). STAT3 activity is inhibited by Ruxolitinib, inducing apoptosis and reducing cisplatin resistance in nonsmall-cell lung cancer (NSCLC) cell lines (72). AZD1480, another FDA-approved JAK2 inhibitor for myeloproliferative disease treatment, also displays significant pSTAT3 reduction in solid tumours, reducing growth of many cell lines with constitutive STAT3 activity (73). Furthermore, JAK2 specific inhibitors such as 
Pancritinib are in the final stages of clinical trials for myelofibrosis and display increased potency compared to currently available JAK inhibitors (74).

\subsection{Directly inhibiting STAT3}

Despite persistent attempts by many laboratories and pharmaceutical companies to develop STAT3 inhibitors, this has yet to be satisfactorily achieved raising the question of whether STAT3 is truly a druggable target. Many direct STAT3 inhibitors have been identified or produced using a variety of techniques, including screens of large compound libraries, computer assisted virtual screening with the STAT3 crystal structure, optimization of natural STAT3 inhibitor compounds and STAT3- binding peptides, and fragment-based drug design and drug repositioning using multiple ligand simultaneous docking (MLSD) (75-77). These inhibitors can be placed into three broad groups; peptides, small molecules and oligonucleotides. All groups act on STAT3 through targeting one of three STAT3 motifs namely the N-terminal domain, the SH2 domain and the DNA binding domain (DBD) (Figure 3). Peptide inhibitors mimic STAT3 binding protein sequences to interrupt protein-protein interactions and can be directed towards all three sites. SH2 domain peptide inhibitors, for example, are based on the SH2 domain binding motif pTyr-Xxx-Xxx-Gln (where Xxx represents any amino acid) $(47,78)$. The majority of small molecule inhibitors are claimed to bind the STAT3 SH2 domain although some are directed towards the DBD (79-81). In contrast oligonucleotide decoy inhibitors, that resemble the STAT3 DNA binding site in the c-fos promoter, act solely on the STAT3 DBD to prevent DNA binding and transcriptional activation (55).

Thus, there are a number of STAT3 domains that are potentially targetable by therapeutics and these will be discussed in more detail below.

\section{Targetable STAT3 Domains}

\subsection{The $\mathrm{N}$-terminal domain}

The N-terminal coiled-coil domain interface is formed of 4 helices that are grouped to form a hook-like structure and is responsible for protein-protein interactions and formation of multiple oligomers (82). Here, two STAT3 DNA-bound dimers interact to form a transcription initiating tetramer $(7,8)$. In addition this region is required for 
successful nuclear shuttling of phosphorylated and unphosphorlyated STAT3 monomers (83). ST3-H2A2, a synthetic peptide discovered from a library directed towards STAT3 N-Domain binding, successfully binds at this site to specifically inhibit STAT3 function but not that of STAT1. The N-Domain of STAT1 displays considerable differences in sequence to STAT3, and therefore is not recognised by the tailored peptide. ST3-H2A2 modified regulation of STAT3 gene targets, increasing expression of 17 pro-apoptotic genes and inducing apoptosis (84). Furthermore, ST3$\mathrm{H} 2 \mathrm{~A} 2$ could be made more membrane permeable by tagging the $\mathrm{C}$-terminus to Penetratin, a 16 amino acid peptide internalized by cells (85).

\subsection{The SH2 domain}

The STAT3 SH2 domain is a 100 amino acid sequence containing three solventavailable subpockets that can interact with activated receptors and a second STAT3 monomer $(9,82)$. These pockets interact with key sites, the pTyr-705, the adjacent leucine residue and additional hydrophobic residues on a second STAT3 monomer to stabilize STAT3 dimer interactions. STAT3 SH2 domain inhibitors prevent docking with receptors and dimerization, thereby blocking activation and function (9). Many SH2 domain-binding peptides have been synthesized with high potency, some with IC50 values in the low nanomolar range (78). For example, PY*LKTK-mts and APT $_{\text {STAT3-9R potently inhibit STAT3 activation and dimerization, inhibiting tumour }}$ cell growth and inducing apoptosis in vitro and in vivo (47). STA-21, a small molecule discovered from a virtual screen of over 400,000 compounds against the STAT3 SH2 domain, inhibits STAT3 activity and DNA binding at $20 \mu \mathrm{M}$ and has completed phase II clinical trials as a topical agent for STAT3 driven psoriasis (75, 86). LLL-12, an optimized analogue of STA-21, blocked STAT3 activation and DNA binding at $2 \mu \mathrm{M}$, suppressing tumour growth and inducing apoptosis (87). Stattic, another small molecule STAT3 SH2 domain inhibitor, was discovered in a fluorescent polarization (FP) compound screen against the STAT3 $\mathrm{SH} 2$ domain and inhibits STAT3 DNA binding at $10 \mu \mathrm{M}$ with specificity over STAT1 (79). BP-1-102, a structurally modified analogue of S31-201, displays binding to all three subpockets of the STAT3 SH2 domain and inhibits STAT3 activity at $20 \mu \mathrm{M}$, reducing growth and invasion of multiple tumour cell line xenografts (9). Inhibitors claiming to inhibit the 
STAT3 SH2 domain are the most numerous of all STAT3 inhibitors with many other notable examples (88).

\subsection{DNA binding domain}

The STAT3 DNA-binding domain (DBD) is constituted of four loops originating from the DBDs and linker domains from each STAT3 monomer (82). Inhibitors binding here impede STAT3 binding to target DNA sequences and thus gene expression. Peptide inhibitors directed towards the STAT3 DBD, discovered through yeast two hybrid display of STAT3 DBD, inhibited STAT3 transcriptional activity with high potency, inhibiting growth and inducing apoptosis of human myeloma cells (89). InS3-54, a small molecule STAT3 DBD inhibitor discovered through a virtual screen against the crystal structure of STAT3ß-complexed to DNA, also inhibited STAT3 transcriptional activity in a time and dose dependent manner (90). Decoy oligonucleotides, closely resembling STAT3 DNA binding sites, bind STAT3 dimers and prevent nuclear localisation and DNA binding. One such example induced apoptosis and growth inhibition in many cancerous cell lines with constitutive STAT3 activity but did not affect normal cells (55). In a recent phase 0 trial this STAT3 decoy oligonucleotide proved to have tolerable toxicology and promising efficacy in xenograft models and in humans, inhibiting STAT3 gene targets in patients with HNSCC and reducing the tumour growth (55).

\section{Why have STAT3 inhibitors not reached the clinic?}

Despite these achievements the question remains as to why no STAT3 inhibitors have reached the clinic. Peptide therapeutics, although specific and highly potent, suffer from rapid degradation and instability, although considerable progress has been made into improving peptide pharmacokinetic and pharmacodynamic profiles (91). SH2 domain binding peptidomimetics also require phosphorylated tyrosine residues to bind to the STAT3 SH2 domain, an essential negative charge that limits cell membrane penetrance, drastically reducing efficacies in vitro and in vivo (47). Poor membrane permeability can also be improved however, by the addition of membrane translocating sequences or further modification $(47,85)$. Modified STAT3 specific peptides may yet provide a viable option for targeting STAT3 in vivo, although as yet, the aforementioned limitations has meant that none have moved into clinical trials. In contrast, small molecules efficiently cross the membrane. However, FDA-approved 
small molecule inhibitors are dominated by kinase inhibitors that mimic the structure of ATP and bind the deep hydrophobic ATP binding cleft, a site that STAT3 lacks. The three inhibitory sites mentioned above are large, planar surfaces that prove difficult for small molecules to bind to specifically and block the large protein-protein interactions. Many small molecule "STAT3 inhibitors", identified from virtual and high-through-put screens, displayed unsaturated ketone groups that can be responsible for forming non-specific bonds with nucleophilic groups of peptides (92). The binding affinity of Stattic to STAT3, for example, was dramatically reduced in the presence of $2 \mathrm{mM}$ DTT, a strong nucleophile, suggesting electron donation saturates the electrophilic group of Stattic and prevents effective STAT3 binding. Furthermore, inhibition was reduced when a nitro group of Stattic, a strong electron acceptor, was replaced with $\mathrm{NH}_{2}$ or $\mathrm{H}$ (79). This raises the question; are STAT3 specific inhibitors binding specifically or adhering to protein surfaces non-specifically? The majority of STAT3 SH2 domain small molecule inhibitors are lacking crucial evidence of specific STAT3 binding. Despite this caveat, there are a number of small molecule STAT3 inhibitors currently undergoing clinical trials, such as STA-21 for the treatment of psoriasis. OPB-31121 and OPB-51602 have also completed phase I trials for the treatment of advanced cancer $(93,94)$. DNA oligonucleotide therapeutics suffer poor bioavailability, poor pharmacokinetics and short half-lives in vivo due to rapid nuclease degradation, which has meant very few have reached the clinic (95). The half-life of the unmodified STAT3 decoy oligonucleotide was short but could be extended following 5 ' and $3^{\prime}$ end modification to create a cyclic molecule, inhibiting degradation (55). Other oligonucleotide therapeutics have been modified at the phosphate backbone to increase stability and reduce degradation in vivo (95). Membrane permeability and tissue specific delivery have remained problematic for all oligonucleotide therapies however, and has thus limited clinical use (96).

\section{STAT3 therapeutics: future perspectives}

Evidence continues to accumulate that STAT3 is an oncogene and an important target for therapy. Recent analysis of the six main breast cancer subtypes, basal-like, luminal A, luminal B, ERBB2/HER2+, normal breast-like and claudin low, suggests constitutive STAT3 activity is predominantly associated with basal-like breast cancers (97). This important finding re-establishes STAT3 as a desirable therapeutic target, as basal-like breast cancer often lacks the three treatable breast cancer markers, estrogen 
receptor (ER), progesterone receptor (PR) and human epidermal growth factor receptor 2 (HER2) (98). However, despite intensive efforts, STAT3 has remained frustratingly elusive as a target for cancer therapy. There are a large number of STAT3 inhibitors currently undergoing clinical trials, which shows that with technological advances and the continuous improvement to all approaches, progress is being made. However, the lack of a clinically applicable STAT3 inhibitor has brought to light the problems still being encountered. Lack of cell penetrance, lack of binding specificity and rapid degradation are some examples of the problems that have needed to be addressed. Most inhibitors and methods of delivery described in this review will require more research and development if they are to become the next generation of cancer therapies. A non-specific compound is likely to cause off target effects resulting in cytotoxicity and a likely failure in clinical trials. Whereas a molecule that is too rapidly degraded in vivo, or that lacks membrane permeability will undoubtedly lack efficacy in a clinical setting. Nevertheless, providing clinicians with an addition to the armamentarium in the fight against therapy-resistant cancer will always justify the resources and effort required to develop a STAT3 specific therapeutic.

\section{Acknowledgements}

MSW is supported by a BBSRC CASE PhD studentship with GlaxoSmithKline. We apologize to authors whose work we have not cited due to space constraints and the extensive literature on this topic.

\section{Figure legends}

Figure 1. A linear diagram depicting functional STAT3 domainsN-Domain, coiledcoil domain, DNA binding domain, linker domain, $\mathrm{SH} 2$ domain and transactivation domain are all presented with amino acid numbers indicating boundaries between each. Phosphorylation sites Tyr705 and Ser727 and acetylation site Lys685 are also displayed.

Figure 2. The activation and regulation of the STAT3 pathway. Binding of stimulatory ligands to cell surface receptors induces members of the JAK family to cross-phosphorylate each other and then specific domains on the cytokine receptors. This provides binding sites for the recruitment and phosphorylation of STAT3 monomers. STAT3 can be activated also by receptor and non-receptor tyrosine kinases such as EGFR and Src respectively. Phosphorylated STAT3 monomers homodimerize and translocate to the nucleus where they bind DNA and regulate 
transcription of target genes. STAT3 signalling is regulated via many negative feedback controls. SOCS members, some of which are directly upregulated by STAT3, bind either to JAKs or to receptor-binding sites where they compete with STAT3. PIAS members lead to direct degradation of STAT3 protein while phosphatases, such as PTP and SHP-1, lead to dephosphoryation of kinases and STAT3 to inhibit signalling.

Figure 3. Schematic diagram of the DNA bound STAT3 $\beta$ homodimer complex and potential binding sites for inhibitor compounds on the STAT3 $\beta$ monomer. The STAT3-DNA complex (PDB code 1BG1) with the N-terminal oligomerization domain depicted in green, DNA binding domain in orange, linker domain in blue, $\mathrm{SH} 2$ domain in red and C-terminal phosphotyrosine containing region in grey. A. A solid surface view of entire complex viewed from along the DNA axis. B. Ribbon surface STAT3 $\beta$-DNA complex close up view along DNA axis. C. Solid surface view of STAT3 $\beta$ monomer and potential inhibitor binding sites with examples. This figure was designed using the program Chimera. Inhibitor compounds are referenced in the text. 


\section{References}

1. Choi JY, Li WL, Kouri RE, Yu J, Kao FT, Ruano G. Assignment of the acute phase response factor (APRF) gene to $17 \mathrm{q} 21$ by microdissection clone sequencing and fluorescence in situ hybridization of a P1 clone. Genomics. 1996;37(2):264-5.

2. Maritano D, Sugrue ML, Tininini S, Dewilde S, Strobl B, Fu X, et al. The STAT3 isoforms alpha and beta have unique and specific functions. Nature immunology. 2004;5(4):401-9.

3. Yoo JY, Huso DL, Nathans D, Desiderio S. Specific ablation of Stat3beta distorts the pattern of Stat3-responsive gene expression and impairs recovery from endotoxic shock. Cell. 2002;108(3):331-44.

4. Chakraborty A, Tweardy DJ. Granulocyte colony-stimulating factor activates a $72-\mathrm{kDa}$ isoform of STAT3 in human neutrophils. Journal of leukocyte biology. 1998;64(5):675-80.

5. Hevehan DL, Miller WM, Papoutsakis ET. Differential expression and phosphorylation of distinct STAT3 proteins during granulocytic differentiation. Blood. 2002;99(5):1627-37.

6. Ren Z, Mao X, Mertens C, Krishnaraj R, Qin J, Mandal PK, et al. Crystal structure of unphosphorylated STAT3 core fragment. Biochem Biophys Res Commun. 2008;374(1):1-5.

7. Vinkemeier U, Cohen SL, Moarefi I, Chait BT, Kuriyan J, Darnell JE, Jr. DNA binding of in vitro activated Stat 1 alpha, Stat1 beta and truncated Stat1: interaction between NH2-terminal domains stabilizes binding of two dimers to tandem DNA sites. The EMBO journal. 1996;15(20):5616-26.

8. $\mathrm{Xu} \mathrm{X}$, Sun YL, Hoey T. Cooperative DNA binding and sequence-selective recognition conferred by the STAT amino-terminal domain. Science. 1996;273(5276):794-7.

9. Zhang X, Yue P, Page BD, Li T, Zhao W, Namanja AT, et al. Orally bioavailable small-molecule inhibitor of transcription factor Stat3 regresses human breast and lung cancer xenografts. Proc Natl Acad Sci U S A. 2012;109(24):9623-8.

10. Akira S, Nishio Y, Inoue M, Wang XJ, Wei S, Matsusaka T, et al. Molecular cloning of APRF, a novel IFN-stimulated gene factor 3 p91-related transcription factor involved in the gp130-mediated signaling pathway. Cell. 1994;77(1):63-71.

11. Claudinon J, Gonnord P, Beslard E, Marchetti M, Mitchell K, Boularan C, et al. Palmitoylation of interferon-alpha (IFN-alpha) receptor subunit IFNAR1 is required for the activation of Stat1 and Stat2 by IFN-alpha. J Biol Chem. 2009;284(36):24328-40.

12. Berclaz G, Altermatt HJ, Rohrbach V, Siragusa A, Dreher E, Smith PD. EGFR dependent expression of STAT3 (but not STAT1) in breast cancer. International journal of oncology. 2001;19(6):1155-60.

13. Cao X, Tay A, Guy GR, Tan YH. Activation and association of Stat3 with Src in v-Src-transformed cell lines. Molecular and cellular biology. 1996;16(4):1595-603.

14. Hemmann U, Gerhartz C, Heesel B, Sasse J, Kurapkat G, Grotzinger J, et al. Differential activation of acute phase response factor/Stat3 and Stat 1 via the cytoplasmic domain of the interleukin 6 signal transducer gp130. II. Src homology SH2 domains define the specificity of stat factor activation. J Biol Chem. 1996;271(22):12999-3007.

15. Ho HH, Ivashkiv LB. Role of STAT3 in type I interferon responses. Negative regulation of STAT1-dependent inflammatory gene activation. J Biol Chem. 2006;281(20):14111-8. 
16. Schuringa JJ, Schepers H, Vellenga E, Kruijer W. Ser727-dependent transcriptional activation by association of p300 with STAT3 upon IL-6 stimulation. FEBS Lett. 2001;495(1-2):71-6.

17. Huang Y, Qiu J, Dong S, Redell MS, Poli V, Mancini MA, et al. Stat3 isoforms, alpha and beta, demonstrate distinct intracellular dynamics with prolonged nuclear retention of Stat3beta mapping to its unique C-terminal end. J Biol Chem. 2007;282(48):34958-67.

18. Lee H, Zhang P, Herrmann A, Yang C, Xin H, Wang Z, et al. Acetylated STAT3 is crucial for methylation of tumor-suppressor gene promoters and inhibition by resveratrol results in demethylation. Proc Natl Acad Sci $U$ S A. 2012;109(20):7765-9.

19. Kang K, Robinson GW, Hennighausen L. Comprehensive meta-analysis of Signal Transducers and Activators of Transcription (STAT) genomic binding patterns discerns cell-specific cis-regulatory modules. BMC genomics. 2013;14:4.

20. Starr R, Willson TA, Viney EM, Murray LJ, Rayner JR, Jenkins BJ, et al. A family of cytokine-inducible inhibitors of signalling. Nature. 1997;387(6636):917-21.

21. Chung CD, Liao J, Liu B, Rao X, Jay P, Berta P, et al. Specific inhibition of Stat3 signal transduction by PIAS3. Science. 1997;278(5344):1803-5.

22. $\mathrm{Xu} \mathrm{D}, \mathrm{Qu}$ CK. Protein tyrosine phosphatases in the JAK/STAT pathway. Front Biosci. 2008;13:4925-32.

23. Watson CJ, Miller WR. Elevated levels of members of the STAT family of transcription factors in breast carcinoma nuclear extracts. British journal of cancer. 1995;71(4):840-4.

24. Migone TS, Lin JX, Cereseto A, Mulloy JC, O'Shea JJ, Franchini G, et al. Constitutively activated Jak-STAT pathway in T cells transformed with HTLV-I. Science. 1995;269(5220):79-81.

25. Weber-Nordt RM, Egen C, Wehinger J, Ludwig W, Gouilleux-Gruart V, Mertelsmann R, et al. Constitutive activation of STAT proteins in primary lymphoid and myeloid leukemia cells and in Epstein-Barr virus (EBV)-related lymphoma cell lines. Blood. 1996;88(3):809-16.

26. Bromberg JF, Horvath CM, Besser D, Lathem WW, Darnell JE. Stat3 activation is required for cellular transformation by v-src. Mol Cell Biol. 1998;18(5):2553-8.

27. Bromberg JF, Wrzeszczynska MH, Devgan G, Zhao Y, Pestell RG, Albanese C, et al. Stat3 as an oncogene. Cell. 1999;98(3):295-303.

28. Dechow TN, Pedranzini L, Leitch A, Leslie K, Gerald WL, Linkov I, et al. Requirement of matrix metalloproteinase-9 for the transformation of human mammary epithelial cells by Stat3-C. Proceedings of the National Academy of Sciences of the United States of America. 2004;101(29):10602-7.

29. Barbieri I, Pensa S, Pannellini T, Quaglino E, Maritano D, Demaria M, et al. Constitutively active Stat 3 enhances neu-mediated migration and metastasis in mammary tumors via upregulation of Cten. Cancer research. 2010;70(6):2558-67.

30. Xu Q, Briggs J, Park S, Niu G, Kortylewski M, Zhang S, et al. Targeting Stat3 blocks both HIF-1 and VEGF expression induced by multiple oncogenic growth signaling pathways. Oncogene. 2005;24(36):5552-60.

31. Buettner R, Mora LB, Jove R. Activated STAT signaling in human tumors provides novel molecular targets for therapeutic intervention. Clin Cancer Res. 2002;8(4):945-54.

32. Garcia R, Bowman TL, Niu G, Yu H, Minton S, Muro-Cacho CA, et al. Constitutive activation of Stat3 by the Src and JAK tyrosine kinases participates in 
growth regulation of human breast carcinoma cells. Oncogene. 2001;20(20):2499513.

33. Pilati C, Amessou M, Bihl MP, Balabaud C, Nhieu JT, Paradis V, et al. Somatic mutations activating STAT3 in human inflammatory hepatocellular adenomas. J Exp Med. 2011;208(7):1359-66.

34. Garcia R, Yu CL, Hudnall A, Catlett R, Nelson KL, Smithgall T, et al. Constitutive activation of Stat 3 in fibroblasts transformed by diverse oncoproteins and in breast carcinoma cells. Cell growth \& differentiation : the molecular biology journal of the American Association for Cancer Research. 1997;8(12):1267-76.

35. Regis G, Pensa S, Boselli D, Novelli F, Poli V. Ups and downs: the STAT1:STAT3 seesaw of Interferon and gp130 receptor signalling. Seminars in cell \& developmental biology. 2008;19(4):351-9.

36. Demaria M, Giorgi C, Lebiedzinska M, Esposito G, D'Angeli L, Bartoli A, et al. A STAT3-mediated metabolic switch is involved in tumour transformation and STAT3 addiction. Aging (Albany NY). 2010;2(11):823-42.

37. Ogura H, Murakami M, Okuyama Y, Tsuruoka M, Kitabayashi C, Kanamoto $\mathrm{M}$, et al. Interleukin-17 promotes autoimmunity by triggering a positive-feedback loop via interleukin-6 induction. Immunity. 2008;29(4):628-36.

38. Dauer DJ, Ferraro B, Song L, Yu B, Mora L, Buettner R, et al. Stat3 regulates genes common to both wound healing and cancer. Oncogene. 2005;24(21):3397-408.

39. Park SJ, Nakagawa T, Kitamura H, Atsumi T, Kamon H, Sawa S, et al. IL-6 regulates in vivo dendritic cell differentiation through STAT3 activation. Journal of immunology. 2004;173(6):3844-54.

40. Takeda K, Clausen BE, Kaisho T, Tsujimura T, Terada N, Forster I, et al. Enhanced Th1 activity and development of chronic enterocolitis in mice devoid of Stat3 in macrophages and neutrophils. Immunity. 1999;10(1):39-49.

41. Nefedova Y, Huang M, Kusmartsev S, Bhattacharya R, Cheng P, Salup R, et al. Hyperactivation of STAT3 is involved in abnormal differentiation of dendritic cells in cancer. Journal of immunology. 2004;172(1):464-74.

42. Kortylewski M, Kujawski M, Wang T, Wei S, Zhang S, Pilon-Thomas S, et al. Inhibiting Stat3 signaling in the hematopoietic system elicits multicomponent antitumor immunity. Nature medicine. 2005;11(12):1314-21.

43. Dercamp C, Chemin K, Caux C, Trinchieri G, Vicari AP. Distinct and overlapping roles of interleukin-10 and CD25+ regulatory $\mathrm{T}$ cells in the inhibition of antitumor CD8 T-cell responses. Cancer Res. 2005;65(18):8479-86.

44. Viguier M, Lemaitre F, Verola O, Cho MS, Gorochov G, Dubertret L, et al. Foxp3 expressing CD4+CD25(high) regulatory T cells are overrepresented in human metastatic melanoma lymph nodes and inhibit the function of infiltrating $\mathrm{T}$ cells. $\mathrm{J}$ Immunol. 2004;173(2):1444-53.

45. Chan KS, Sano S, Kiguchi K, Anders J, Komazawa N, Takeda J, et al. Disruption of Stat 3 reveals a critical role in both the initiation and the promotion stages of epithelial carcinogenesis. The Journal of clinical investigation. 2004;114(5):720-8.

46. Amin HM, McDonnell TJ, Ma Y, Lin Q, Fujio Y, Kunisada K, et al. Selective inhibition of STAT3 induces apoptosis and G(1) cell cycle arrest in ALK-positive anaplastic large cell lymphoma. Oncogene. 2004;23(32):5426-34.

47. Turkson J, Ryan D, Kim JS, Zhang Y, Chen Z, Haura E, et al. Phosphotyrosyl peptides block Stat3-mediated DNA binding activity, gene regulation, and cell transformation. J Biol Chem. 2001;276(48):45443-55. 
48. Hao W, Hu Y, Niu C, Huang X, Chang CP, Gibbons J, et al. Discovery of the catechol structural moiety as a Stat3 SH2 domain inhibitor by virtual screening. Bioorganic \& medicinal chemistry letters. 2008;18(18):4988-92.

49. Iwamaru A, Szymanski S, Iwado E, Aoki H, Yokoyama T, Fokt I, et al. A novel inhibitor of the STAT3 pathway induces apoptosis in malignant glioma cells both in vitro and in vivo. Oncogene. 2007;26(17):2435-44.

50. Gao LF, Wen LJ, Yu H, Zhang L, Meng Y, Shao YT, et al. Knockdown of Stat3 expression using RNAi inhibits growth of laryngeal tumors in vivo. Acta Pharmacol Sin. 2006;27(3):347-52.

51. Kunigal S, Lakka SS, Sodadasu PK, Estes N, Rao JS. Stat3-siRNA induces Fas-mediated apoptosis in vitro and in vivo in breast cancer. International journal of oncology. 2009;34(5):1209-20.

52. Zhang H, Cai K, Wang J, Wang X, Cheng K, Shi F, et al. MiR-7, inhibited indirectly by lincRNA HOTAIR, directly inhibits SETDB1 and reverses the EMT of breast cancer stem cells by downregulating the STAT3 pathway. Stem Cells. 2014;32(11):2858-68.

53. Liu RY, Zeng Y, Lei Z, Wang L, Yang H, Liu Z, et al. JAK/STAT3 signaling is required for TGF-beta-induced epithelial-mesenchymal transition in lung cancer cells. International journal of oncology. 2014;44(5):1643-51.

54. Demaria M, Giorgi C, Lebiedzinska M, Esposito G, D'Angeli L, Bartoli A, et al. A STAT3-mediated metabolic switch is involved in tumour transformation and STAT3 addiction. Aging (Albany NY). 2010;2(11):823-42.

55. Sen M, Thomas SM, Kim S, Yeh JI, Ferris RL, Johnson JT, et al. First-inhuman trial of a STAT3 decoy oligonucleotide in head and neck tumors: implications for cancer therapy. Cancer Discov. 2012;2(8):694-705.

56. Park JS, Kwok SK, Lim MA, Kim EK, Ryu JG, Kim SM, et al. STA-21, a promising STAT-3 inhibitor that reciprocally regulates Th17 and Treg cells, inhibits osteoclastogenesis in mice and humans and alleviates autoimmune inflammation in an experimental model of rheumatoid arthritis. Arthritis \& rheumatology. 2014;66(4):918-29.

57. Spitzner M, Roesler B, Bielfeld C, Emons G, Gaedcke J, Wolff HA, et al. STAT3 inhibition sensitizes colorectal cancer to chemoradiotherapy in vitro and in vivo. International journal of cancer Journal international du cancer. 2014;134(4):9971007.

58. Alas S, Bonavida B. Inhibition of constitutive STAT3 activity sensitizes resistant non-Hodgkin's lymphoma and multiple myeloma to chemotherapeutic drugmediated apoptosis. Clinical cancer research : an official journal of the American Association for Cancer Research. 2003;9(1):316-26.

59. Nguyen KB, Salazar-Mather TP, Dalod MY, Van Deusen JB, Wei XQ, Liew FY, et al. Coordinated and distinct roles for IFN-alpha beta, IL-12, and IL-15 regulation of $\mathrm{NK}$ cell responses to viral infection. Journal of immunology. 2002;169(8):4279-87.

60. Huang S, Bucana CD, Van Arsdall M, Fidler IJ. Stat1 negatively regulates angiogenesis, tumorigenicity and metastasis of tumor cells. Oncogene. 2002;21(16):2504-12.

61. Dabir S, Kluge A, Kresak A, Yang M, Fu P, Groner B, et al. Low PIAS3 Expression in Malignant Mesothelioma Is Associated with Increased STAT3 Activation and Poor Patient Survival. Clinical cancer research : an official journal of the American Association for Cancer Research. 2014;20(19):5124-32. 
62. Yoshikawa H, Matsubara K, Qian GS, Jackson P, Groopman JD, Manning JE, et al. SOCS-1, a negative regulator of the JAK/STAT pathway, is silenced by methylation in human hepatocellular carcinoma and shows growth-suppression activity. Nat Genet. 2001;28(1):29-35.

63. Hu Y, Hong Y, Xu Y, Liu P, Guo DH, Chen Y. Inhibition of the JAK/STAT pathway with ruxolitinib overcomes cisplatin resistance in non-small-cell lung cancer NSCLC. Apoptosis : an international journal on programmed cell death. 2014;19(11):1627-36.

64. Graham J, Muhsin M, Kirkpatrick P. Cetuximab. Nature reviews Drug discovery. 2004;3(7):549-50.

65. Zhang Q, Wang HY, Marzec M, Raghunath PN, Nagasawa T, Wasik MA. STAT3- and DNA methyltransferase 1-mediated epigenetic silencing of SHP-1 tyrosine phosphatase tumor suppressor gene in malignant T lymphocytes. Proc Natl Acad Sci U S A. 2005;102(19):6948-53.

66. Sethi G, Chatterjee S, Rajendran P, Li F, Shanmugam MK, Wong KF, et al. Inhibition of STAT3 dimerization and acetylation by garcinol suppresses the growth of human hepatocellular carcinoma in vitro and in vivo. Mol Cancer. 2014;13:66.

67. Boehm AL, Sen M, Seethala R, Gooding WE, Freilino M, Wong SM, et al. Combined targeting of epidermal growth factor receptor, signal transducer and activator of transcription-3, and Bcl-X(L) enhances antitumor effects in squamous cell carcinoma of the head and neck. Mol Pharmacol. 2008;73(6):1632-42.

68. Bhargava R, Gerald WL, Li AR, Pan Q, Lal P, Ladanyi M, et al. EGFR gene amplification in breast cancer: correlation with epidermal growth factor receptor mRNA and protein expression and HER-2 status and absence of EGFR-activating mutations. Mod Pathol. 2005;18(8):1027-33.

69. Levine RL, Pardanani A, Tefferi A, Gilliland DG. Role of JAK2 in the pathogenesis and therapy of myeloproliferative disorders. Nature reviews Cancer. 2007;7(9):673-83.

70. Mesa RA. Ruxolitinib, a selective JAK1 and JAK2 inhibitor for the treatment of myeloproliferative neoplasms and psoriasis. IDrugs. 2010;13(6):394-403.

71. Chase A, Bryant C, Score J, Haferlach C, Grossmann V, Schwaab J, et al. Ruxolitinib as potential targeted therapy for patients with JAK2 rearrangements. Haematologica. 2013;98(3):404-8.

72. Hu Y, Hong Y, Xu Y, Liu P, Guo DH, Chen Y. Inhibition of the JAK/STAT pathway with ruxolitinib overcomes cisplatin resistance in non-small-cell lung cancer NSCLC. Apoptosis. 2014;19(11):1627-36.

73. Hedvat M, Huszar D, Herrmann A, Gozgit JM, Schroeder A, Sheehy A, et al. The JAK2 inhibitor AZD1480 potently blocks Stat3 signaling and oncogenesis in solid tumors. Cancer Cell. 2009;16(6):487-97.

74. Duong VH, Komrokji RS. The role of pacritinib in the management of myelofibrosis. Expert Rev Hematol. 2014;7(3):325-32.

75. Schust J, Berg T. A high-throughput fluorescence polarization assay for signal transducer and activator of transcription 3. Analytical biochemistry. 2004;330(1):1148.

76. Siddiquee K, Zhang S, Guida WC, Blaskovich MA, Greedy B, Lawrence HR, et al. Selective chemical probe inhibitor of Stat3, identified through structure-based virtual screening, induces antitumor activity. Proceedings of the National Academy of Sciences of the United States of America. 2007;104(18):7391-6.

77. Li H, Liu A, Zhao Z, Xu Y, Lin J, Jou D, et al. Fragment-based drug design and drug repositioning using multiple ligand simultaneous docking (MLSD): 
identifying celecoxib and template compounds as novel inhibitors of signal transducer and activator of transcription 3 (STAT3). Journal of medicinal chemistry. 2011;54(15):5592-6.

78. Dhanik A, McMurray JS, Kavraki LE. Binding modes of peptidomimetics designed to inhibit STAT3. PLoS One. 2012;7(12):e51603.

79. Schust J, Sperl B, Hollis A, Mayer TU, Berg T. Stattic: a small-molecule inhibitor of STAT3 activation and dimerization. Chemistry \& biology. 2006;13(11):1235-42.

80. Turkson J, Zhang S, Mora LB, Burns A, Sebti S, Jove R. A novel platinum compound inhibits constitutive Stat3 signaling and induces cell cycle arrest and apoptosis of malignant cells. The Journal of biological chemistry. 2005;280(38):32979-88.

81. Song H, Wang R, Wang S, Lin J. A low-molecular-weight compound discovered through virtual database screening inhibits Stat 3 function in breast cancer cells. Proceedings of the National Academy of Sciences of the United States of America. 2005;102(13):4700-5.

82. Ren Z, Mao X, Mertens C, Krishnaraj R, Qin J, Mandal PK, et al. Crystal structure of unphosphorylated STAT3 core fragment. Biochem Biophys Res Commun. 2008;374(1):1-5.

83. Pranada AL, Metz S, Herrmann A, Heinrich PC, Muller-Newen G. Real time analysis of STAT3 nucleocytoplasmic shuttling. The Journal of biological chemistry. 2004;279(15):15114-23.

84. Timofeeva OA, Tarasova NI, Zhang X, Chasovskikh S, Cheema AK, Wang H, et al. STAT3 suppresses transcription of proapoptotic genes in cancer cells with the involvement of its N-terminal domain. Proceedings of the National Academy of Sciences of the United States of America. 2013;110(4):1267-72.

85. Timofeeva OA, Gaponenko V, Lockett SJ, Tarasov SG, Jiang S, Michejda CJ, et al. Rationally designed inhibitors identify STAT3 N-domain as a promising anticancer drug target. ACS chemical biology. 2007;2(12):799-809.

86. Miyoshi K, Takaishi M, Nakajima K, Ikeda M, Kanda T, Tarutani M, et al. Stat3 as a therapeutic target for the treatment of psoriasis: a clinical feasibility study with STA-21, a Stat3 inhibitor. The Journal of investigative dermatology. 2011;131(1):108-17.

87. Lin L, Hutzen B, Li PK, Ball S, Zuo M, DeAngelis S, et al. A novel small molecule, LLL12, inhibits STAT3 phosphorylation and activities and exhibits potent growth-suppressive activity in human cancer cells. Neoplasia. 2010;12(1):39-50.

88. Miklossy G, Hilliard TS, Turkson J. Therapeutic modulators of STAT signalling for human diseases. Nature reviews Drug discovery. 2013;12(8):611-29.

89. Nagel-Wolfrum K, Buerger C, Wittig I, Butz K, Hoppe-Seyler F, Groner B. The interaction of specific peptide aptamers with the DNA binding domain and the dimerization domain of the transcription factor Stat3 inhibits transactivation and induces apoptosis in tumor cells. Molecular cancer research : MCR. 2004;2(3):17082.

90. Huang W, Dong Z, Wang F, Peng H, Liu JY, Zhang JT. A small molecule compound targeting STAT3 DNA-binding domain inhibits cancer cell proliferation, migration, and invasion. ACS chemical biology. 2014;9(5):1188-96.

91. Goodwin D, Simerska P, Toth I. Peptides as therapeutics with enhanced bioactivity. Current medicinal chemistry. 2012;19(26):4451-61.

92. Debnath B, Xu S, Neamati N. Small molecule inhibitors of signal transducer and activator of transcription 3 (Stat3) protein. J Med Chem. 2012;55(15):6645-68. 
93. Goh BC, Wong ALA, Soo RA, Kong LR, Zee YK, Chuah B, et al. Phase I study of OPB51602, a small molecule inhibitor of STAT3 phosphorylation, in patients with refractory solid malignancies. J Clin Oncol. 2012;30(15).

94. Bendell JC, Hong DS, Burris HA, 3rd, Naing A, Jones SF, Falchook G, et al. Phase 1, open-label, dose-escalation, and pharmacokinetic study of STAT3 inhibitor OPB-31121 in subjects with advanced solid tumors. Cancer chemotherapy and pharmacology. 2014;74(1):125-30.

95. Dias N, Stein CA. Antisense oligonucleotides: basic concepts and mechanisms. Molecular cancer therapeutics. 2002;1(5):347-55.

96. Lee SH, Castagner B, Leroux JC. Is there a future for cell-penetrating peptides in oligonucleotide delivery? European journal of pharmaceutics and biopharmaceutics : official journal of Arbeitsgemeinschaft fur Pharmazeutische Verfahrenstechnik eV. 2013;85(1):5-11.

97. Tell RW, Horvath CM. Bioinformatic analysis reveals a pattern of STAT3associated gene expression specific to basal-like breast cancers in human tumors. Proceedings of the National Academy of Sciences of the United States of America. 2014;111(35):12787-92.

98. Badve S, Dabbs DJ, Schnitt SJ, Baehner FL, Decker T, Eusebi V, et al. Basallike and triple-negative breast cancers: a critical review with an emphasis on the implications for pathologists and oncologists. Modern pathology : an official journal of the United States and Canadian Academy of Pathology, Inc. 2011;24(2):157-67. 


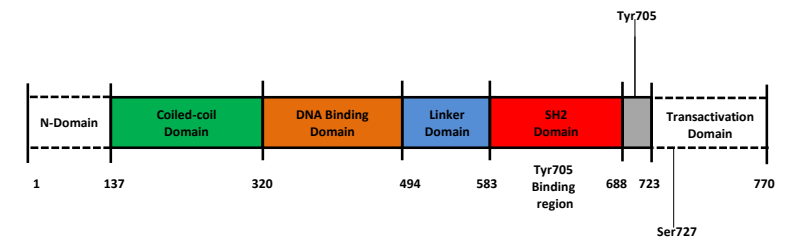




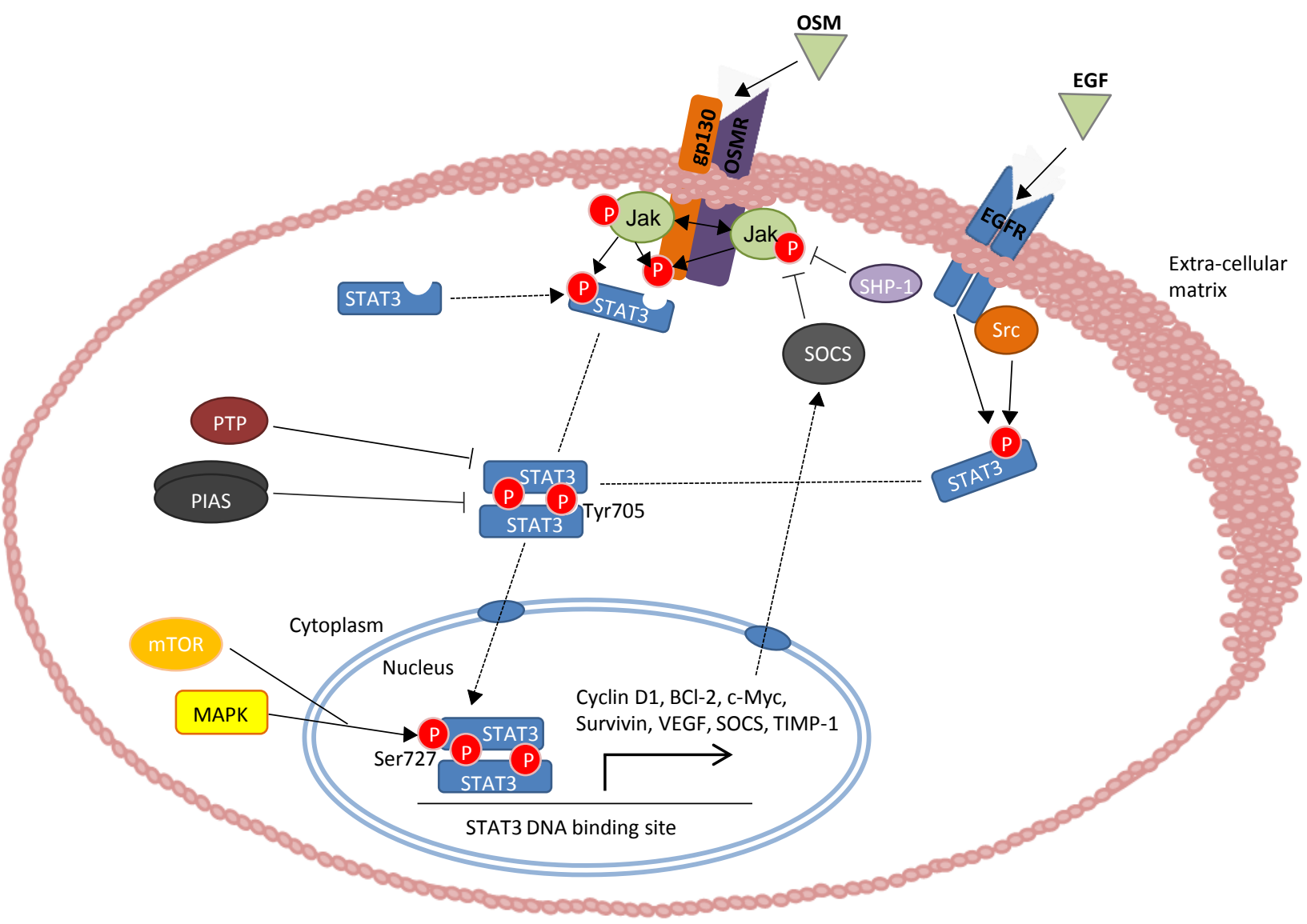



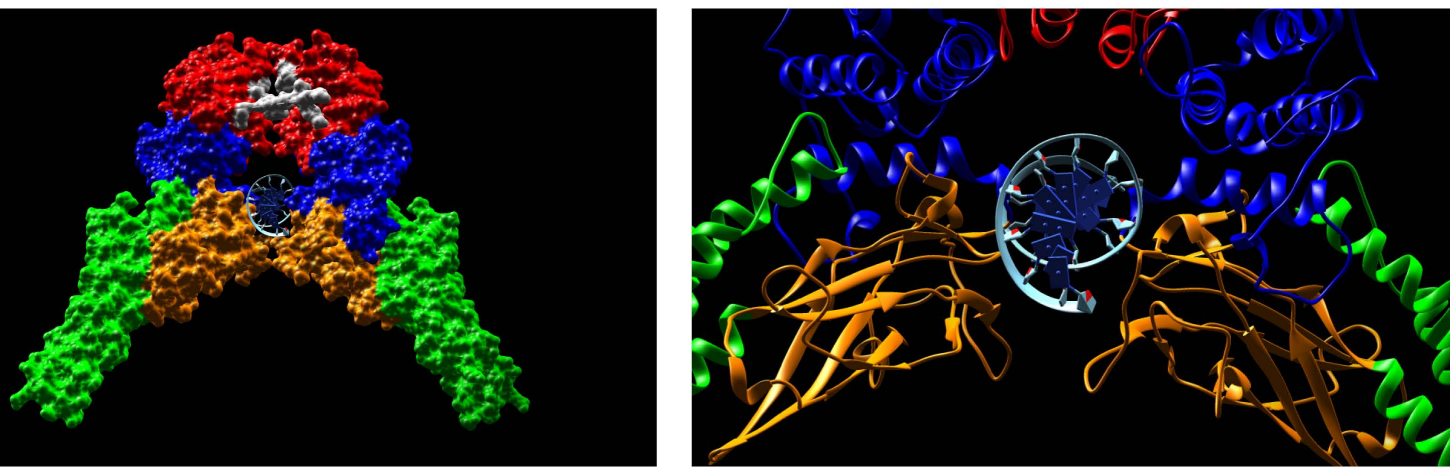

The SH2 Domain

PY*LKTK

ISS-610

STA-21

Stattic

S31-201

LLL-12

Curcumin

\section{The DNA binding domain}

STAT3 decoy oligonucleotide DBD1

IS3-295

HIC 1

InS3-54 